\title{
Measurement of microbial nitrogen flow in the duodenum in sheep
}

\author{
WZ Yang, C Poncet \\ INRA de Theix, laboratoire de la Dynamique de la Digestion, \\ 63122 Saint-Genès-Champanelle, France
}

The microbial nitrogen (N) in the duodenum is normally estimated by the marker ratio technique, using the concentration of the marker in the liquid associated bacteria $(L A B)$ isolated from the rumen or sometimes from the duodenal contents as reference. It implicitly assumes that $\mathrm{LAB}$ are representative of the total microbial mass present in the rumen, which is now known to be incorrect (Merry and Mc Allan, 1983; Yang et al, 1989). We report here the preliminary data which allow an estimation of the error resulting from this assumption.

Four 2-yr-old wethers fitted with rumen and duodenal cannulae were successively given the same amounts $(1210 \mathrm{~g}$ DM/d in equal meals at 3-h intervals) of 4 isonitrogenous diets composed of good-quality orchard grass hay and concentrate-either dehydrated beet pulp or corn grain-in the ratios $70 / 30$ and $40 / 60$ on a (DM basis). Chemical composition and distribution of $\mathrm{LAB}$ and adherent biomasses expressed as "solid adherent bacteria equivalent" (SABeq, assuming sampled $S A B$ were representative of the entire adherent population of SAB and fungi) in each wet-sieved particle pool were determined in the rumen and in the duodenum as described by Yang et al (1989). Cr-EDTA and $15 \mathrm{~N}$, continuously infused for $5 \mathrm{~d}$ and $3 \mathrm{~d}$ respectively before sampling, were used as flow and microbial markers. $\angle A B$ biomasse in the rumen effluent was estimated as: rumen $L A B$ poof $x$ rumen water fractional outflow rate, and that of SABeq as the concentration of SABeq on each size of rumen particles $x$ duodenal DM flow of these particles. ${ }^{15} \mathrm{~N}$ enrichments of the microbial matter flowing from the rumen was then calculated as the sum of the enrichments in $\angle A B$ and $S A B$ from each particle pool, weighted according to their proportion in the total biomass. Dividing the NA-15N duodenal flow by this enrichment (Method 3) gave an estimate of the actual flow which was compared to that calculated using rumen (Method1) or duodenal (Method 2) enrichment of $L A B$ alone.

As expected, the more reliable Method 3 always provided higher microbial $\mathrm{N}$ flow than the currently used Method 1 (18.4 vs $15.6 \mathrm{~g} \mathrm{~N} / \mathrm{d}$; $18 \%$ increase, $P<0.05$; means of 4 diets). Method 2 gave the same estimates $(18.4 \mathrm{~g} \mathrm{~N} / \mathrm{d})$ as Method 3 because of the shift in duodenal LAB-15N enrichment towards that of the more representative microbial sampling of Method 3 . The 3 methods showed the same diet effect.

In conclusion, Method 3 is not a reference method because it assumes that protozoa and fungi have the same ${ }^{15} \mathrm{~N}$ enrichment as SAB. However, it can be concluded that the commonly-used method is inadequate and must be improved upon.

Merry RJ, Mc Allan AB (1983) Br J Nutr 50, 701709

Yang WZ, Poncet C, Escobar A (1989) Asian J Agric Sci 2, 394-395 